\title{
Interactions between shoal size and conformity in guppy social foraging
}

\author{
RACHEL L. DAY, TOM MACDONALD, CULUM BROWN, KEVIN N. LALAND \& SIMON M. READER \\ Sub-Department of Animal Behaviour, Department of Zoology, University of Cambridge
}

(Received 12 June 2000; initial acceptance 25 July 2000;

final acceptance 30 June 2001; MS. number: 6606R)

\begin{abstract}
Previous experimental studies have established that shoaling fish forage more effectively in large than small groups. We investigated how shoal size affects the foraging efficiency of laboratory populations of the guppy, Poecilia reticulata, exposed to different foraging tasks. Experiment 1 confirmed the prediction that in open water the first fish and focal fish of larger shoals locate food faster than in smaller shoals. However, a second experiment, in which shoals of fish were required to swim through a hole in an opaque partition to locate food, found the reverse pattern: smaller shoals learned to complete the task faster than large shoals. Experiment 3, in which shoals of various sizes were exposed to a transparent maze partition, clarified the apparent contradictory results of the first two experiments, with larger shoals again learning to complete the task faster than small shoals. The findings of experiments 2 and 3 can be explained in terms of positive frequency-dependent social learning, or conformity. This facilitated social learning in large groups in experiment 3 where visual contact could be maintained through the partition, but hindered it in experiment 2 where visual contact was lost once a fish had passed through the partition. The findings raise the possibility that novel behavioural innovations, particularly those that require individuals to break contact with the group, may be more likely to spread in smaller than larger groups of animals.
\end{abstract}

(C) 2001 The Association for the Study of Animal Behaviour

The fitness payoffs of group living in animals are commonly thought to depend upon the risk of predation as well as on the balance between foraging costs and benefits (Pitcher \& Parrish 1993). Individuals that forage in groups may incur costs associated with enhanced competition for food, time-wasting social interactions, kleptoparasitism and declining food intake rate with an increased probability of foraging from recently depleted resources (Beecham \& Farnsworth 1999). However, a common feature of social foraging is that the food discoveries of a few lead to the feeding of many, and group living may enable individuals to forage more efficiently through information transfer (Ward \& Zahavi 1973) and social learning (Zentall \& Galef 1988; Heyes \& Galef 1996). In addition, although large groups may attract predators, they may also reduce per capita predation

Correspondence: R. L. Day, Sub-Department of Animal Behaviour, Department of Zoology, University of Cambridge, Madingley, Cambridge CB3 8AA, U.K. (email: rd245@cus.cam.ac.uk). C. Brown is now at the Ashworth Laboratories, Institute of Cell, Animal and Population Biology, University of Edinburgh, Kings Buildings, Edinburgh EH9 3JT, U.K. S. M. Reader is now at the Department of Biology, McGill University, 1205 Avenue Docteur Penfield, Montrèal, Quèbec H3A 1B1, Canada.

pressures through increased group vigilance, dilution, confusion and selfish-herd mechanisms (Hamilton 1971; Pulliam 1973; Bertram 1978). Large groups provide 'many eyes' for predator detection, but the increased numbers of observers may also increase the probability that a given food source will be detected (Pulliam 1973; Bertram 1978; Lazarus 1979) and any reduction in predation pressure resulting from aggregation may translate into the conversion of vigilance time to foraging time (Pulliam 1973; Bertram 1978).

Animals frequently use information produced by other individuals, or 'public information' (Giraldeau 1997); indeed, such information transfer has been hypothesized as one function of group formation (Ward \& Zahavi 1973; but see Richner \& Heeb 1995). Learning from public information is termed 'social learning', that is, learning from others (Box 1984; Heyes 1994). Processes through which social learning can take place that are of particular relevance to this paper are 'local enhancement' or 'area copying', where an individual directs its behaviour towards a location where others are currently active, and 'stimulus enhancement' or 'object copying', where an individual directs its behaviour towards an object that matches the type attended to by others (Whiten \& Ham 
1992; Giraldeau 1997). Social learning should be distinguished from processes of social interaction where no learning takes place, such as social facilitation. Social facilitation describes the situation where the presence of other individuals enhances the performance of behaviour patterns already in an individual's repertoire, for example because isolation-induced fear is reduced (Galef 1988). Information transfer and social learning have long been of interest to ethologists and behavioural ecologists because such processes appear to enable onlookers to exploit information gained by others and allow animals to learn about their environments rapidly and efficiently, without making costly mistakes or wasting time on exploration.

In shoaling fish the behaviour of individuals is strongly influenced by the presence of predators and number of conspecifics present, with the resulting feeding strategies a compromise between various costs and benefits (Hart 1993). By foraging in large shoals, fish can detect and monitor an approaching predator more easily and can continue feeding for longer than fish in smaller shoals (Milinski 1993). For example, goldfish, Carassius auratus, and minnows, Phoxinus phoxinus, are more timid and spend less time foraging when in smaller shoals (Magurran \& Pitcher 1983). Members of large but not small shoals of bluntnose minnows, Pimephales notatus, will feed at an elevated rate when hungry if a predator is present (Morgan 1988). It seems likely that reductions in predation risk associated with group living will tend to increase foraging efficiency in fish living in large groups (Morgan \& Colgan 1987; Morgan 1988).

It is now well established that social learning (Laland \& Williams 1997, 1998), local enhancement (Pitcher \& House 1987; Ryer \& Olla 1992) and social facilitation (Ryer \& Olla 1992) can enhance foraging efficiency in shoaling fish. Goldfish, minnows and pollack, Pollachius spp., all locate food patches more efficiently with increasing shoal size (Pitcher et al. 1982; Morgan \& Colgan 1987; Pitcher \& House 1987; Morgan 1988; Ryer \& Olla 1991, 1992). Provided that fish acquire up-to-date foraging information from their shoalmates, social learning may be partly responsible for this improvement in performance (Pitcher \& House 1987; Ryer \& Olla 1991, 1992; Laland \& Williams 1997). Thus a preliminary consideration of the effects of social-learning processes would also lead to the prediction that larger shoals of fish will locate food more rapidly than smaller shoals.

We examined the effect of shoal size upon the efficacy of social foraging in the guppy, Poecilia reticulata, using three different foraging tasks and various shoal sizes that fall within the range of that seen in the wild (Magurran \& Seghers 1994). In experiment 1 we examined whether the established relationship of increased shoal size enhancing foraging efficiency in fish is found among guppies searching for food patches in open water. In experiment 2 we explored the effect of shoal size on the rate at which guppies learn to complete a more complex foraging task, in which they had to negotiate a simple maze to locate food. In a third experiment we used a transparent maze to help clarify the apparently conflicting findings of experiments 1 and 2 .

\section{EXPERIMENT 1: DO LARGER SHOALS LOCATE FOOD FASTER?}

In this experiment, we tested adult female guppies in differing shoal sizes to determine whether fish in larger shoals found food faster than those in smaller shoals. Shoals of fish were presented with a task in which they were required to locate food that could be contained in one of six feeders in their tanks. The dependent variables were the latency for the first fish and a focal fish to enter the baited feeder and feed, thus reflecting the average time for the whole shoal. We tested 12 focal fish once each in shoals of size two, four, eight and 16 guppies, giving a repeated measures design.

\section{Methods}

\section{Subjects and apparatus}

We purchased guppies from Neil Hardy Aquatica, London, U.K. We used domestic guppies as the diverse coloration of these fish makes identification possible without stressful marking procedures. There is no evidence that the behaviour of domestic strains of guppy differs from that of the wild type, and social learning has been found in natural populations of the guppy (Reader 1999). There is also evidence that guppies in the field can learn the location of a food source by approaching feeding conspecifics (Reader 1999). Twelve adult female guppies acted as focal fish with a further 100 adult females acting as 'shoalmates'. We used an additional 12 adult female guppies as 'companion fish' to the focal fish. The companion fish accompanied the focal fish in the experimental tank during between-trial periods to prevent stress associated with isolation. All subjects were experimentally naïve and we used only females to rule out confounding effects of sexual interactions, and because the experimental evidence for social learning in guppies is more compelling in this sex.

During the pretraining period the 112 fish were housed together in two populations of approximately equal numbers in two glass holding tanks $(91 \times 29 \mathrm{~cm}$ and $39 \mathrm{~cm}$ high) with water level $25 \mathrm{~cm}$, maintained at ca. $25^{\circ} \mathrm{C}$. The fish were on a 12:12 h light:dark schedule, with lights on at 0700 hours; additional red lights were on continuously, ensuring the switch in lighting caused minimal disturbance to the fish. During the 4 days when tests were conducted, each focal fish was housed in one of 12 experimental tanks $(61 \times 39 \mathrm{~cm}$ and $30 \mathrm{~cm}$ high), which were visually isolated with white polystyrene. During the experiments six opaque white feeders $(6.5 \times 10.5 \mathrm{~cm}$ and $7.5 \mathrm{~cm}$ high) were placed in the tanks, two at the water surface and one at the tank floor at each end of the experimental tank (Fig. 1a). The box-like feeders were designed so that subjects could not see whether it contained food until they were inside the feeder. The food consisted of blocks of freeze-dried Tubifex which floated within the surface feeders or was pressed on to the inside ceiling of the bottom feeder. Fish could gain access to the food only by swimming through a hole $(10.5 \times 1.5 \mathrm{~cm})$ at the bottom of the feeder and upwards towards the food. 
(a)

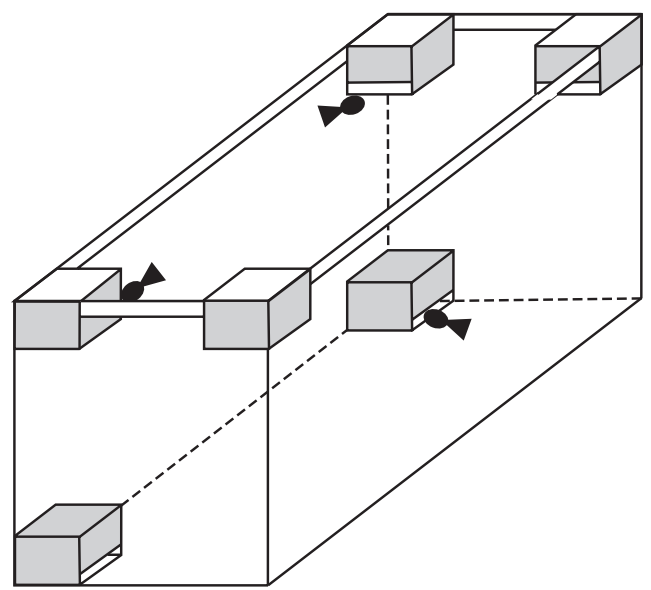

(b)

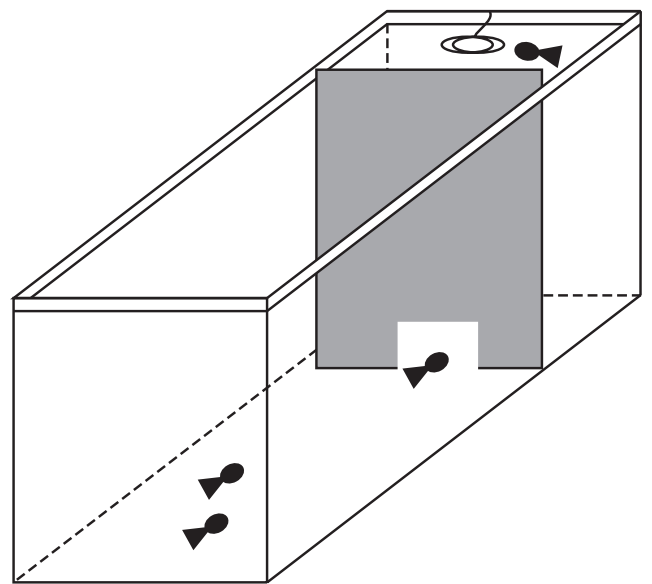

Figure 1. (a) Experiment 1 set-up showing the position of the six feeders. The entrance of the top feeders faced the opposite short side of the tank and the entrance of the bottom feeders faced the opposite long side of the tank; the rear side of the latter was the glass side of the tank facing the experimenter. (b) Apparatus for experiment 2. Fish were required to swim from the large compartment, through the hole in the opaque partition, into the small compartment and feed at a floating feeder.

\section{Procedure}

Pretraining occurred prior to the selection of the 12 focal fish. Once a day for 4 consecutive days we placed a bottom feeder and a surface feeder, each containing up to three $1-\mathrm{cm}^{3}$ cubes of Tubifex, whole or crushed respectively, into each of the housing tanks at a random location. Fish were allowed to feed at the feeders for 10 min before we removed the feeding boxes. After 4 days all fish in the holding tanks were competent at entering the feeders and feeding, and appeared to associate the feeders with food.

After pretraining, we chose the 12 focal fish at random and placed them into 12 experimental tanks with their companions (which were not from the pool of pretrained fish). Subjects and companion fish were allowed $24 \mathrm{~h}$ undisturbed to acclimatize to the tank. Once a day for the next 4 days we removed the companion fish to a holding tank and we added either one, three, seven or 15 fish from the holding tanks to form the appropriate shoal sizes. The order in which each focal fish was included in a shoal size was randomized. Each shoal was formed just $2 \mathrm{~h}$ prior to a trial to prevent any confounding effects of familiarity (schooling preferences for familiar fish vary with group size), since familiarity takes several days to acquire (Griffiths \& Magurran 1997).

After the settling period we shepherded the fish into the centre of the tank with two opaque partitions placed $15 \mathrm{~cm}$ from either end of the tank, and we introduced six feeders to each tank behind the partitions. Only one feeder contained food. The baiting of the feeder was balanced such that for each shoal size a specific feeder was used as the target feeder twice only. We released the fish from the central compartment by manually raising the two partitions (causing minimal disturbance to the fish), and recorded the latency to enter the target feeder and to feed for the first fish in each shoal as well as the focal fish. We terminated the trial when these four recordings had been taken or after 10 min had elapsed, whichever occurred sooner.

After testing, we placed all shoalmate fish at random into one of the two holding tanks, and returned the companion fish to the appropriate experimental tanks. The use of a pool of fish in this manner ensured that, although each fish might have been used more than once, the shoals comprised different individuals and thus were independent.

Statistical tests are two tailed.

\section{Results and Discussion}

The four dependent variables present a consistent picture (Fig. 2). There were significant differences between the shoal sizes in the latency for the first fish in each shoal to enter the feeder (ANOVA: $F_{3,33}=11.742, P<0.01$ ) and to feed $\left(F_{3,33}=10.078, P<0.01\right)$, and in the latency for the focal fish to enter the feeder $\left(F_{3,33}=3.729, P<0.025\right)$ and to feed $\left(F_{3,33}=3.068, P<0.05\right)$. As shoal size increased from two to 16 , individual latencies reduced in a linear fashion for the first fish in each shoal to enter the feeder (linear trend analysis: $F_{1,11}=55.957, P<0.01$ ) and feed $\left(F_{1,11}=30.449, P<0.01\right)$, and the focal fish to enter the feeder $\left(F_{1,11}=27.079, P<0.01\right)$ and feed $\left(F_{1,11}=10.118\right.$, $P<0.01)$. There were significant differences (Fisher's PLSD) between all shoal sizes except four and eight, for measurements of the first fish in each shoal (that is, $16<8=4<2$, see Fig. 2 for details) However, there were significant differences only between shoal sizes 16 and two for measurements of the focal fish (that is, $16<2$ ). 

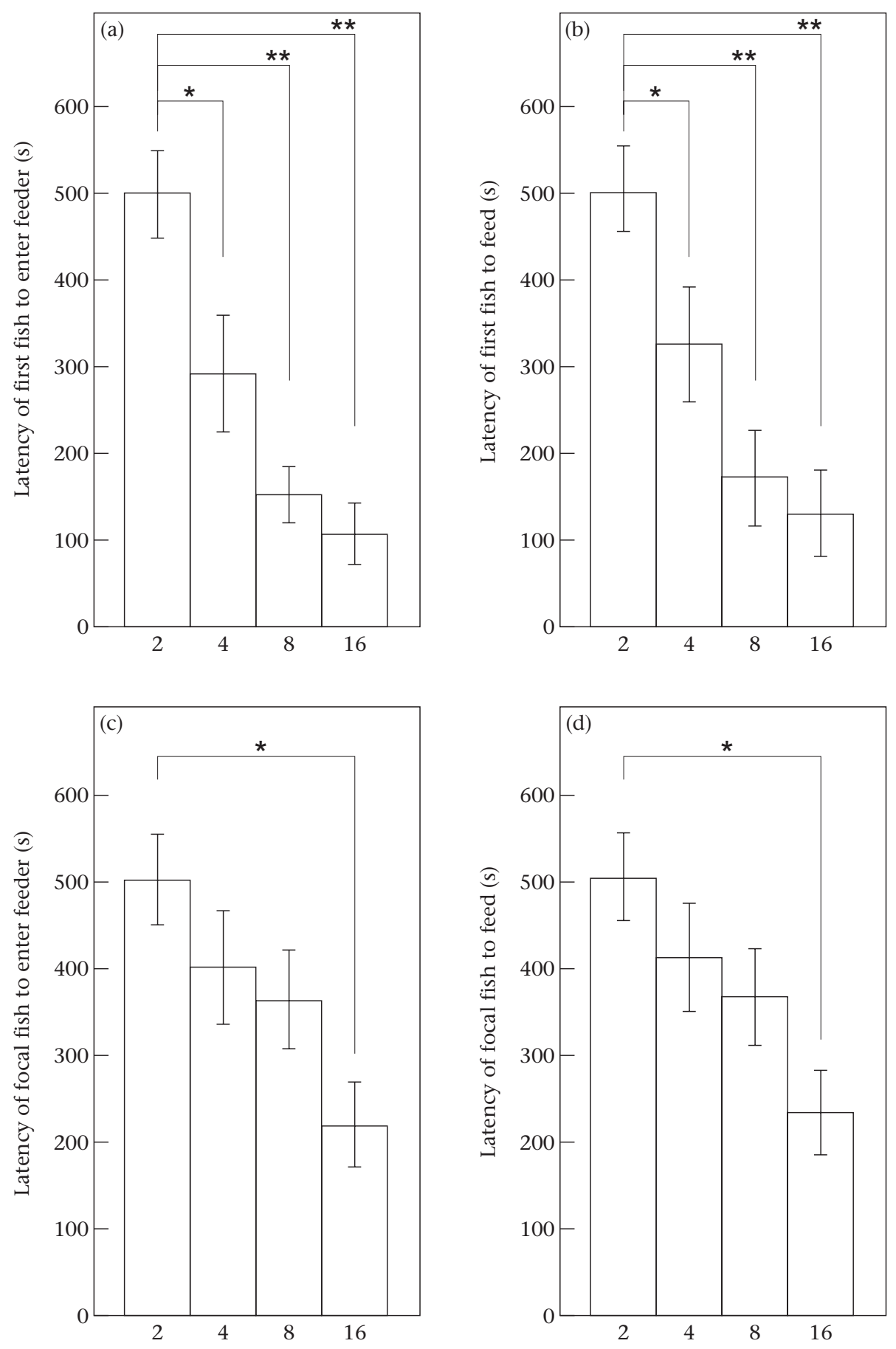

Shoal size

Figure 2. Mean latencies $\pm S E$ of each shoal size, for (a) the first fish to enter the feeder, (b) the first fish to feed, (c) the focal fish to enter the feeder and (d) the focal fish to feed. $N=12$ in each case. (LSD: ${ }^{*} P<0.05 ;{ }^{*} P<0.01$ ).

This experiment clearly shows that foraging efficiency in guppies is influenced positively by increased shoal size and is consistent with the findings of many other studies of social foraging in fish (Pitcher et al. 1982; Magurran \& Pitcher 1983; Pitcher \& House 1987; Morgan 1988; Ryer $\&$ Olla 1992). The finding that the first fish in each shoal to find food did so more rapidly with increased shoal size could be due to a combination of factors. If each fish is assumed to search at random, as shoal size increases the probability of more rapid patch discovery will also increase. In addition, since the fish were pretrained to expect to find food when the feeders were introduced to the tank, increased foraging efficiency with increased shoal size could be due to the social facilitation of the motivation to feed (Ryer \& Olla 1992). The presence of other foraging individuals could simply increase the 
individual's attention to the task of food location (Ryer \& Olla 1992), increase foraging because of the perceived increased level of foraging competition (Krause 1993) or reduce conflicting motivational forces, such as fear of predation (Morgan 1988; Ryer \& Olla 1992).

The finding that the focal fish located food faster in larger shoals but was not necessarily the first to the food is also suggestive of local enhancement. The design of the experiment, for which the fish knew when but not where the food was available, might have encouraged individuals to monitor the behaviour and movements of conspecifics. Fish in larger shoals have more shoalmates from which to acquire information than those in small shoals and should, on average, find food faster by following the social cues emanating from successful foragers. We anticipate that the first individual to locate food may effectively 'tip-off' the others to the presence of food. Furthermore, if fish search feeders until they locate food, but remain near the baited feeder, this congregation will generate a flow of traffic towards the baited feeder, a process described as 'exposure' (Whiten \& Ham 1992). As a result of this aggregation, other foragers may rapidly converge on the food site, via local enhancement. As fish can be seen crowding around the feeder, in larger shoals the increased number of successful foragers will provide a more salient demonstration of feeding behaviour to other fish (Laland \& Williams 1997), becoming more attractive to join (Lachlan et al. 1998), and thus will recruit hitherto unsuccessful foragers more rapidly.

\section{EXPERIMENT 2: EFFECT OF SHOAL SIZE WITH OPAQUE PARTITION}

In this experiment adult female guppies in shoals of four, eight or 16 fish were presented with a simple maze task to determine how shoal size affected foraging performance when social cues emanating from successful foragers could not be used. We repeatedly presented shoals of fish with a task in which they were required to locate food by swimming through a hole in an opaque partition and into a goal zone containing a floating feeder. Previous studies have suggested that social learning may be responsible for guppies learning this particular task (Reader \& Laland 2000). Here the dependent variables were the latency for each fish to enter the goal zone and feed. We tested 20 shoals of fish over 15 trials in a repeated measures design.

\section{Methods}

\section{Subjects and apparatus}

The subjects were 176 experimentally naïve adult female guppies purchased from Neil Hardy Aquatica, London, U.K.

The experimental tanks measured $61 \times 39 \mathrm{~cm}$ and $30 \mathrm{~cm}$ high, with water depth $25 \mathrm{~cm}$, and were maintained at $25^{\circ} \mathrm{C}$ (Fig. 1b). We covered all sides of the tank, except for the one required for observation, with white polystyrene to prevent the fish from being influenced by external events. The maze consisted of an opaque white
PVC partition $(28.5 \times 30 \mathrm{~cm})$ with a centrally located hole $(4 \times 4 \mathrm{~cm})$ at the bottom of the tank, placed $14.5 \mathrm{~cm}$ from one end. We marked the area surrounding the hole with a red crayon to aid visual discrimination. We randomized the position of the partition with respect to the end of the tank, for each group. A floating ring feeder of red plastic $3 \mathrm{~cm}$ diameter and $0.5 \mathrm{~cm}$ depth was secured centrally $5-10 \mathrm{~cm}$ behind the partition. Small quantities of freezedried bloodworm (Chironomus spp.) could be placed inside the feeders, to which the fish could gain access by swimming beneath the ring. When we introduced the apparatus to the tank, we placed an opaque white PVC release partition $(29 \times 30 \mathrm{~cm})$ between the fish and the experimental partition.

\section{Procedure}

We assigned the subjects to one of three shoal sizes: four, eight or 16. To eliminate statistical biases, we created eight shoals of four, six of eight and six of 16 fish. The distinctive size, shape and colour markings of each fish were noted so that all individuals could be recognized.

Prior to testing, we pretrained the shoals of fish to associate the red feeder rings with food. Three times a day for 5 days we introduced the feeder into the tank at a randomly chosen location while the fish were swimming freely. After pretraining, the fish appeared to have associated the feeders with food and were competent at obtaining access to them.

Three times a day, at 4-h intervals, for 5 successive days, we shepherded the fish to one end of the tank behind a release partition, introduced the maze apparatus into the experimental tanks and baited it with food. Each trial began with the removal of the release partition, and we recorded the latency of each fish to swim through the hole in the experimental partition. We terminated a trial when all of the fish in the shoal had swum through the hole or when $10 \mathrm{~min}$ had elapsed, whichever occurred sooner. After the last trial of each day we fed the fish a small amount of Aquarian tropical fish flake food to equalize hunger differences between successful and unsuccessful fish.

To eliminate the confounding effects of the nonindependence of fish within a shoal, we used the mean latency/shoal per trial as the dependent variable in our statistical analyses.

Statistical tests are two tailed.

\section{Results and Discussion}

Figure $3 a$ shows the effect of shoal size on the mean latency of each shoal to pass through the partition and enter the goal zone for each of the 15 trials. There was a significant difference between the three shoal sizes in the mean latency for each shoal across all 15 trials (ANOVA: $\left.F_{2,297}=55.055, P<0.0001\right)$. Further analysis revealed that fish in shoals of 16 took longer to locate food $(\bar{X} \pm \mathrm{SE}=302.6 \pm 19.5 \mathrm{~s})$ than fish in shoals of eight $(135.4 \pm 13.1$ s, LSD: $P<0.0001)$ and fish in shoals of four $(106.3 \pm 10 \mathrm{~s}$, LSD: $P<0.0001)$. However, there was no 

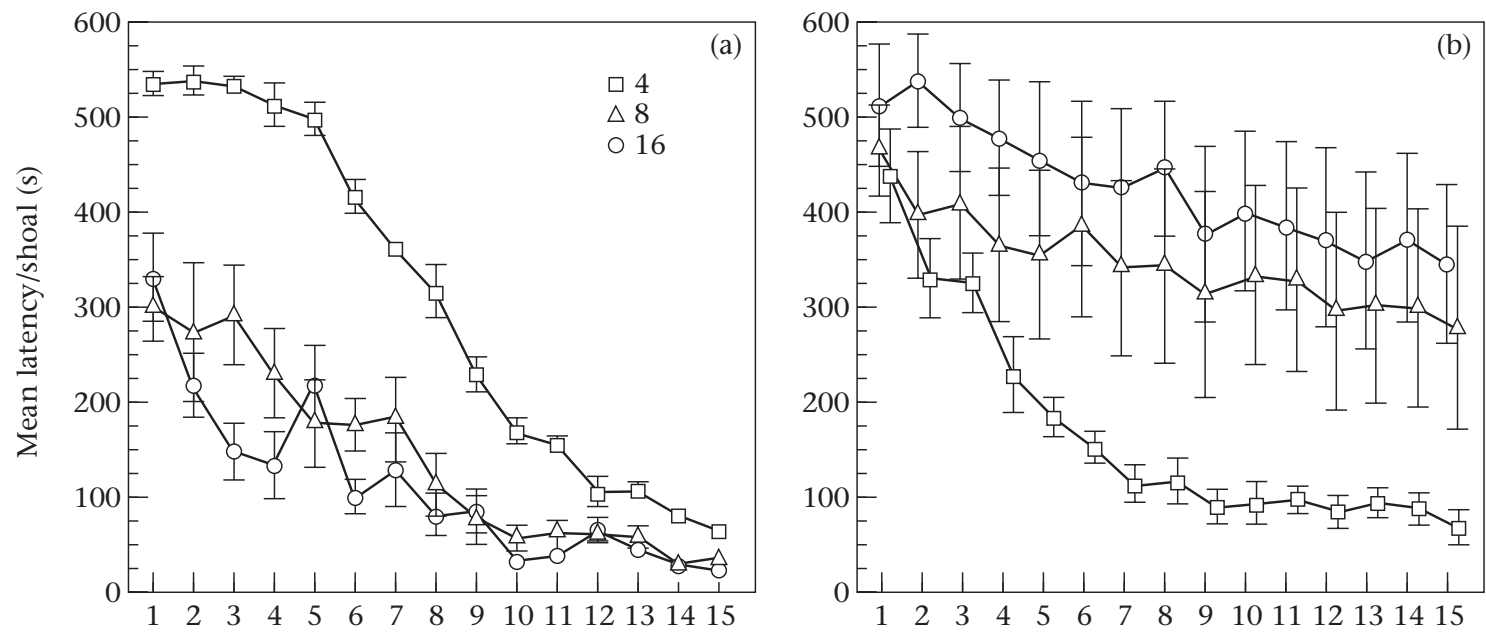

Trial number

Figure 3. Mean shoal latencies \pm SE for fish in each shoal sizes to (a) pass through the opaque partition, in experiment 2 , or (b) pass through the transparent partition, in experiment 3 , to enter the goal zone.

difference between the average times of fish in shoals of four and eight (LSD: $P=0.14$ ). There was a significant change in latency across the 15 trials for shoal size four (ANOVA: $\left.F_{14,105}=11.331, P<0.0001\right)$, eight $\left(F_{14,75}=7.478\right.$, $P<0.0001)$ and $16\left(F_{14,75}=153.297, P<0.0001\right)$, which we construed as evidence for learning as latencies to pass through the partition decreased with increased trial number for shoal sizes of four (linear trend analysis: $\left.F_{1,105}=176.263, P<0.001\right)$, eight $\left(F_{1,75}=87.903, P<0.001\right)$ and 16 fish $\left(F_{1,75}=2058.529, P<0.001\right)$.

The finding that fish took longer to locate food in the larger shoals was unexpected and appears contradictory both to the findings of experiment 1 and to the published literature on shoal size and foraging performance. If the results simply reflected the removal of social cues emanating from successful foragers that would ordinarily attract others towards the foraging patch, we might expect shoals of all sizes to perform equally well (excluding the greater probability of discovering the hole in larger shoals by chance alone). However, the reverse to the predicted trend was observed, with the smaller shoals performing better than the larger shoals.

One explanation stems from the common preference of fish to join larger over smaller shoals (Lindström \& Ranta 1993; Krause \& Godin 1994; Lachlan et al. 1998). A reversal of this logic would suggest that fish may be more ready to leave smaller than larger shoals. In experiment 1 , where there was open water between the feeders, fish could approach a food site without losing sight of other members of their shoal, and a large aggregation of fish at a food site would attract other shoal members to the feeder more effectively than a small aggregation. However, the situation was different in experiment 2, since to locate food fish had to swim through an opaque partition, thereby being forced to break visual contact with their shoalmates, and effectively leave the shoal. From the perspective of an individual leaving the shoal to feed, in the open water of experiment 1 perceived risk increased gradually with increasing distance between the departing individual and the shoal. In experiment 2, however, perceived risk increased sharply as a departing individual passed through the opaque partition where visual contact was lost, and this was true irrespective of distance from the shoal.

Lachlan et al. (1998) argued that a tendency to shoal with the largest number of fish may generate a positive frequency-dependent transmission of foraging information, or conformist transmission (Boyd \& Richerson 1985). The finding that individuals tend to adopt the behaviour of the majority of shoal members (also described as behavioural averaging, Fitzsimmons \& Warburton 1992) would suggest that the most common behaviour will be adopted more rapidly than might otherwise be expected (Lachlan et al. 1998). This frequency dependence represents a conservative force acting against the transmission and subsequent adoption of alternative behaviour patterns, so that the diffusion of novel feeding strategies may be inhibited in large shoals (Lachlan et al. 1998). If we regard swimming through the opaque maze and locating food as a novel feeding strategy, then the earliest fish to swim through the partition would be less likely to be followed in large shoals than in small shoals. For instance, when the first fish enters the hole, an observer in a group of four has a choice between following it or shoaling with two others, while an observer in a group of 16 has the choice of following or shoaling with 14 others. We refer to this account as the 'conformity' explanation, and we specifically designed experiment 3 to test it.

\section{EXPERIMENT 3: EFFECT OF SHOAL SIZE WITH TRANSPARENT PARTITION}

We reasoned that a test of the conformity explanation would be provided by a replication of experiment 2 using an identical design and apparatus except for a transparent maze partition. With a transparent partition, fish entering the goal zone would still be in visual contact with 
their shoalmates in the other section of the tank, and are likely to be regarded as part of the same shoal. Although we did not measure nearest-neighbour distances to confirm shoal membership as defined by Pitcher et al. (1983), it is unlikely that a fish at the feeder was more than the required four body lengths away from a fish in the other section of the tank, as the latter fish tended to be clustered around the partition throughout the trial. Hence, unlike experiment 2, here we did not expect conformity to hinder fish from following their innovative shoalmates through the partition. This led us to predict that latency to feed would decrease with increasing shoal size, as in experiment 1.

\section{Methods}

\section{Subjects and apparatus}

The subjects were 176 experimentally naïve adult female guppies purchased from Neil Hardy Aquatica, London, U.K. The experimental apparatus was identical to that in experiment 2 , except that the maze partition was transparent.

\section{Procedure and analysis}

The procedure and analysis of latencies were as described for experiment 2.

In addition, we analysed the 'following' behaviour of the fish in experiments 2 and 3. In this analysis we considered an individual to have followed another if it passed through the partition within $5 \mathrm{~s}$ of the individual preceding it. Although the choice of a 5-s following latency was arbitrary, our findings hold for following latencies of 1-8 s. When a number of fish entered the goal zone in quick succession each fish was considered to have followed only the fish immediately preceding it rather than all of the fish preceding it. We present these data as the proportion of the number of following events possible. In the case of a shoal of four fish, the second may follow the first, the third may follow the second and the fourth may follow the third fish. The maximum number of following events in any given trial, therefore, is $n-1$, where $n$ equals the shoal size. The total number of following events for all 15 repeated trials was summed for each test shoal.

\section{Results and Discussion}

Figure $3 b$ shows the effect of shoal size on latency to pass through the partition and enter the goal zone over 15 trials. There was a significant difference between the three shoal sizes in the mean latency for each shoal across all 15 trials (ANOVA: $F_{2,297}=46.669, P<0.0001$ ). Further analysis revealed that fish in shoals of size 16 were quicker to locate food $(\bar{X} \pm \mathrm{SE}=166.6 \pm 13.2 \mathrm{~s})$ than either fish in shoals of eight $(346.5 \pm 22.5 \mathrm{~s}$, LSD: $P<0.0001)$ or fish in shoals of four $(424.9 \pm 19.9$ s, LSD: $P<0.0001)$. Fish in shoals of four were slower than those in shoals of eight (LSD: $P=0.004$ ). There was a change in latency across the 15 trials for all shoal sizes, although this was significantly so only for shoals of 16 fish (ANOVA: $F_{14,75}=18.788$,
$P<0.0001$; shoals of $8: F_{14,75}=0.310, P=0.991$, shoals of 4 : $\left.F_{14,105}=0.618, P=0.845\right)$. We again construe this as evidence for learning as latencies to pass through the partition decreased with increased trial number for shoal size four (linear trend analysis: $F_{1,105}=7.952, P<0.01$ ), eight $\left(F_{1,75}=3.723, P<0.01\right)$ and 16 fish $\left(F_{1,75}=227.856\right.$, $P<0.001)$.

Our results support our hypothesis that the opaque partition used in experiment 2 was responsible for reversing the predicted effect of shoal size by breaking visual contact between successful and unsuccessful foragers. As predicted, with a transparent partition, fish in larger shoals located food earlier on average than fish in smaller shoals. This is explained by the observation that, unlike experiment 2, conformity and a greater tendency to remain near larger than smaller shoals no longer hindered the diffusion of foraging information. On the contrary, fish in larger shoals were more likely to have a shoalmate locate the hole because of their greater numbers, and any individual swimming through the hole would be more likely to be followed because they did not break visual contact with the shoal. In addition, as feeding individuals could be seen through the partition, larger shoals benefited from frequency-dependent information transmission. Furthermore, in larger shoals the potentially higher number of fish that could be viewed feeding on the other side of the partition may have facilitated observational learning, social facilitation, local enhancement, or elevated motivation to feed in observing shoalmates.

A direct comparison of experiments 2 and 3 would provide further support for the conformity hypothesis. As expected there was a significant difference in the performance of all equally sized shoals between the opaque condition (Fig. 3a) and the transparent condition (Fig. $3 \mathrm{~b})$ : shoals of 16 took longer to reach the goal zone through the opaque partition $(\bar{X} \pm \mathrm{SE}=302.6 \pm 19.55)$ than through the transparent partition $(166.6 \pm 13.2 \mathrm{~s}$; ANOVA: $\left.F_{1,63}=31.9, \quad P<0.0001\right)$. Conversely shoals of eight and four took longer to pass through the transparent $(346.5 \pm 22.5 \mathrm{~s} ; 424.9 \pm 19.9 \mathrm{~s})$ than the opaque $(135.4 \pm 13.1 \mathrm{~s} ; \quad 106.3 \pm 10.0 \mathrm{~s})$ partitions (ANOVA: $F_{1,178}=65.85, P<0.0001 ; F_{1,238}=203.67, P<0.0001$, respectively). We interpret this pattern of results as resulting from two interacting processes. First, previous experiments in this laboratory have revealed that guppies find transparent mazes more difficult than opaque ones. Therefore the performance of all shoal sizes should be slower in the transparent versus the opaque condition. This is the case for shoals of four and eight. However, the second factor, namely conformity, reduced the performance of shoals of 16 to a greater extent than the smaller shoals in the opaque condition, while in the transparent condition it enhanced the performance of the larger shoals to a greater degree than the smaller shoals.

The conformity explanation suggests that fish in larger shoals are much less likely to follow an individual through the opaque partition than the clear partition, whereas the reverse may be expected in smaller shoals. To test this suggestion we analysed the 'following' behaviour of the fish in experiments 2 and 3. The results of this 


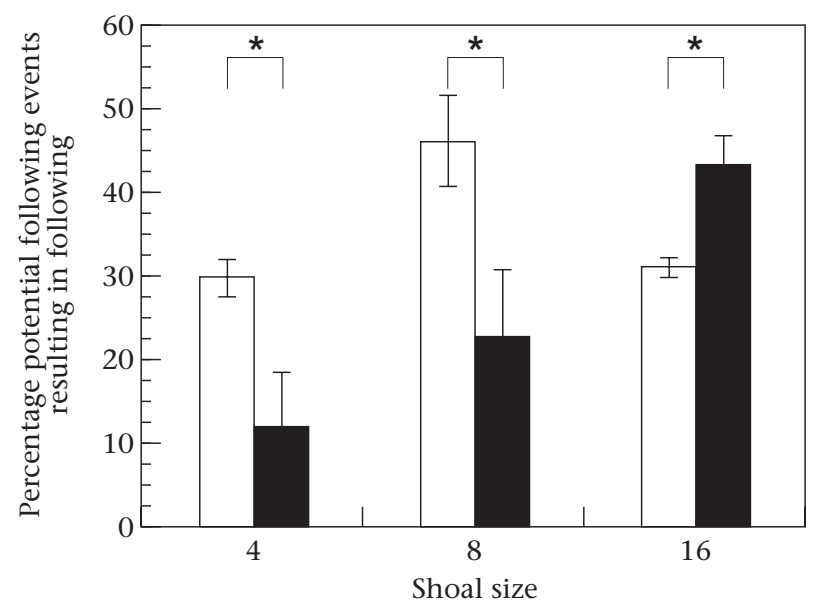

Figure 4. Percentage of potential following events \pm SE that resulted in following as computed by $f / 15(n-1)$ where $f=$ total number of follows in that condition, $n$ is the group size and 15 represents the number of repeated trials for each condition. Data are shown for each shoal size in the opaque ( $\square$; experiment 2 ) and transparent ( $\boldsymbol{\square}$; experiment 3 ) maze conditions. ${ }^{*} P<0.05$; paired $t$ test.

analysis clearly support our predictions (Fig. 4). Paired $t$ tests show that in groups of 16 fish fewer following events occurred with the opaque partition than with the transparent one $\left(t_{5}=3.174, P=0.012\right)$. The reverse was true for shoal sizes of four and eight $\left(t_{8}=2.440, P=0.022\right.$ and $t_{5}=3.858, P=0.006$, respectively). The greatest proportion of following occurred in a shoal size of 16 when the transparent partition was in place $\left(16>4 ; t_{10}=4.060\right.$, $P=0.001$ and $\left.16>8 ; t_{10}=2.407, P=0.023\right)$ whereas shoals of eight had the greatest proportion of following events when the opaque partition was in place $\left(8>16 ; t_{5}=2.721\right.$, $P=0.021$ and $\left.8>4 ; t_{7}=2.309, P=0.027\right)$.

\section{GENERAL DISCUSSION}

Previous experimental studies have established that shoaling fish forage more effectively in large than small groups. The results of experiment 1 were consistent with these findings as in open water larger shoals of guppies on average located food faster than smaller shoals. However, in experiment 2 , in which shoals of guppies were required to swim through a hole in an opaque partition to locate food, we found that smaller shoals completed the task faster than large shoals. The apparent contradiction in these findings can be explained in terms of individuals tending to adopt the most common behaviour pattern and preferring to shoal in larger groups rather than break visual contact with the group.

In experiment 1 conformity accelerated the rate at which large shoals located food relative to small shoals, as large aggregations of fish approaching or at a food site attracted conspecifics to the food more rapidly than smaller aggregations. However, where fish were required to break visual contact with their shoalmates to locate food, as in experiment 2, the presence of a larger shoal on the opposite side of the partition to the feeder deterred individuals from leaving the shoal to locate food, and observers from following them if they did leave the shoal. Hence in experiment 2, at least early on in the trials, conformity compelled fish not to swim through the partition or follow others that did so, but to remain with the shoal, and the strength of this conformity increased with shoal size.

The conformity hypothesis was supported by the findings of experiment 3, where larger shoals found food faster than smaller shoals despite being in a structurally identical apparatus to fish in experiment 2 . The only possible cause of the opposite findings of experiments 2 and 3 was the transparency of the partition, which allowed visual contact to be maintained between fish on either side of the partition in experiment 3 . Thus innovative individuals that solved the maze task, and those that followed them, would not have perceived themselves to be leaving the shoal and would not have been impeded by conformity. Positive frequency-dependent social learning, or conformity, will cause the most common behaviour pattern to be adopted more rapidly than might otherwise be expected, while new behaviours may be slow to spread (Boyd \& Richerson 1985; Lachlan et al. 1998). Therefore in experiment 3 those factors that benefited larger shoals in open water foraging tasks, such as in experiment 1 , came into play.

Frequency-dependent social learning has been demonstrated in guppies (Laland \& Williams 1997; Lachlan et al. 1998), rats, Rattus norvegicus (Beck \& Galef 1989) and pigeons, Columba livia (Lefebvre \& Giraldeau 1994), and may be a common feature of animal social learning (Laland 2000). Our results raise the possibility that novel behavioural innovations, particularly those that require individuals to break contact with the group, may be more likely to spread in smaller groups of animals than larger ones.

\section{Acknowledgments}

This research was supported by a Royal Society University Research Fellowship to K.N.L., a Royal Society grant to C.B., and BBSRC studentships to R.L.D. and S.M.R.

\section{References}

Beck, M. \& Galef, B. G., Jr. 1989. Social influences on the selection of a protein-sufficient diet by Norway rats (Rattus norvegicus). Journal of Comparative Psychology, 103, 132-139.

Beecham, J. A. \& Farnsworth, K. D. 1999. Animal group forces resulting from predator avoidance and competition minimisation. Journal of Theoretical Biology, 198, 533-548.

Bertram, B. C. R. 1978. Living in groups: predators and prey. In: Behavioural Ecology: an Evolutionary Approach (Ed. by J. R. Krebs \& N. B. Davies), pp. 64-69. Oxford: Blackwell Scientific.

Box, H. O. 1984. Primate Behaviour and Social Ecology. London: Chapman \& Hall.

Boyd, R. \& Richerson, P. J. 1985. Culture and the Evolutionary Process. Chicago: University of Chicago Press.

Fitzsimmons, S. D. \& Warburton, K. 1992. Fish movement behaviour: variability within and between groups. Behavioural Processes, 26, 211-216.

Galef, B. G. 1988. Imitation in animals: history, definition, and interpretation of data from the psychological laboratory. In: Social 
Learning: Psychological and Biological Perspectives (Ed. by T. Zentall \& B. G. Galef), pp. 3-25. Hillsdale, New Jersey: L. Erlbaum.

Giraldeau, L. A. 1997. The ecology of information use. In: Behavioural Ecology. 4th edn (Ed. by J. R. Krebs \& N. B. Davies), pp. 42-68. Oxford: Blackwell Scientific.

Griffiths, S. W. \& Magurran, A. E. 1997. Schooling preferences for familiar fish vary with group size in a wild guppy population. Proceedings of the Royal Society of London, Series B, 264, 547-551.

Hamilton, W. D. 1971. Geometry for the selfish herd. Journal of Theoretical Biology, 31, 295-311.

Hart, P. J. B. 1993. Teleost foraging: facts and theories. In: Behaviour of Teleost Fishes. 2nd edn (Ed. by T. J. Pitcher), pp. 253-284. London: Chapman \& Hall.

Heyes, C. M. 1994. Social learning in animals: categories and mechanisms. Biological Reviews, 69, 207-231.

Heyes, C. M. \& Galef, B. G., Jr. 1996. Social Learning in Animals. The Roots of Culture. New York: Academic Press.

Krause, J. 1993. The influence of hunger on shoal size choice by three-spined sticklebacks (Gasterosteus aculeatus). Journal of Fish Biology, 43, 775-780.

Krause, J. \& Godin, J. G. J. 1994. Shoal choice in the banded killifish (Fundulus diaphanus, Teleostei, Cyprinodontidae): effects of predation risk, fish size, species composition and size of shoals. Ethology, 98, 128-136.

Lachlan, R. F., Crooks, L. \& Laland, K. N. 1998. Who follows whom? Shoaling preferences and social learning of foraging information in guppies. Animal Behaviour, 56, 181-190.

Laland, K. N. 2000. Imitation, social learning, and preparedness as mechanisms of bounded rationality. In: Bounded Rationality: The Adaptive Toolbox (Ed. by G. Gingerenzer \& R. Selten), pp. 233247. London: MIT Press.

Laland, K. N. \& Williams, K. 1997. Shoaling generates social learning of foraging information in guppies. Animal Behaviour, 53, 1161-1169.

Laland, K. N. \& Williams, K. 1998. Social transmission of maladaptive information in the guppy. Behavioral Ecology, 9, 493-499.

Lazarus, J. 1979. The early warning function of flocking in birds: an experimental study with captive quelea. Animal Behaviour, 27, 855-865.

Lefebvre, L. \& Giraldeau, L-A. 1994. Cultural transmission in pigeons is affected by the number of tutors and bystanders present. Animal Behaviour, 47, 331-337.

Lindström, K. \& Ranta, E. 1993. Social preferences by male guppies, Poecilia reticulata, based on shoal size and sex. Animal Behaviour, 46, 1029-1031.

Magurran, A. E. \& Pitcher, T. J. 1983. Foraging, timidity and shoal size in minnows and goldfish. Behavioral Ecology and Sociobiology, $12,147-152$.
Magurran, A. E. \& Seghers, B. H. 1994. Predator inspection behaviour covaries with schooling tendency amongst the wild guppy, Poecilia reticulata, populations in Trinidad. Behaviour, 128, 121-134.

Milinski, M. 1993. Predation risk and feeding behaviour. In: Behaviour of Teleost Fishes. 2nd edn (Ed. by T. J. Pitcher), pp. 285-306. London: Chapman \& Hall.

Morgan, M. J. 1988. The influence of hunger, shoal size and predator presence on foraging in bluntnose minnows. Animal Behaviour, 36, 1317-1322.

Morgan, M. J. \& Colgan, P. W. 1987. The effects of predator presence and shoal size on foraging in bluntnose minnows. Environmental Biology of Fishes, 20, 105-111.

Pitcher, T. J. \& House, A. C. 1987. Foraging rules for group feeders: area copying depends upon food density in shoaling goldfish. Ethology, 76, 161-167.

Pitcher, T. J. \& Parrish, J. K. 1993. Functions of shoaling behaviour in teleosts. In: The Behaviour of Teleost Fishes. 2nd edn (Ed. by T. J. Pitcher), pp. 363-440. London: Chapman \& Hall.

Pitcher, T. J., Magurran, A. E. \& Winfield, I. J. 1982. Fish in larger shoals find food faster. Behavioral Ecology and Sociobiology, 10, 149-151.

Pitcher, T. J., Magurran, A. E. \& Allan, J. R. 1983. Shifts of behaviour with shoal size in cyprinids. Proceedings of the Behaviour of Freshwater Fish Conference, 3, 220-228.

Pulliam, H. R. 1973. On the advantages of flocking. Journal of Theoretical Biology, 38, 419-422.

Reader, S. M. 1999. Social learning and innovation: individual differences, diffusion dynamics and evolutionary issues. Ph.D. thesis, Cambridge University.

Reader, S. M. \& Laland, K. N. 2000. Diffusion of foraging innovations in the guppy. Animal Behaviour, 60, 175-180.

Richner, H. \& Heeb, P. 1995. Is the information centre hypothesis a flop? Advances in the Study of Behavior, 24, 1-27.

Ryer, C. H. \& Olla, B. L. 1991. Information transfer and the facilitation and inhibition of feeding in a shoaling fish. Environmental Biology of Fishes, 30, 317-323.

Ryer, C. H. \& Olla, B. L. 1992. Social mechanisms facilitating exploitation of spatially variable ephemeral food patches in a pelagic marine fish. Animal Behaviour, 44, 69-74.

Ward, P. \& Zahavi, A. 1973. The importance of certain assemblages of birds as 'information centres' for food-finding. Ibis, 115, 517 534.

Whiten, A. \& Ham, R. 1992. On the nature of evolution of imitation in the animal kingdom: reappraisal of a century of research. Advances in the Study of Behavior, 21, 239-283.

Zentall, T. R. \& Galef, B. G., Jr. 1988. Social Learning. Psychological and Biological Perspectives. Hillsdale, New Jersey: L. Erlbaum. 